\title{
Association of Cognitive deficits with Optical Coherence Tomography changes in Multiple Sclerosis Patients
}

\author{
Behnaz Sedighi ${ }^{1}$, Mohamad Ali Shafa ${ }^{1}$, Zohreh Abna ${ }^{2}$, Amir Khosrou Ghaseminejad ${ }^{3}$, Reza Farahat ${ }^{4}$, Nozar Nakhaee ${ }^{5}$ and Baharnaz Hassani ${ }^{1}$ \\ ${ }^{1}$ Neurology Research Center, Kerman University of Medical Sciences, Kerman, Iran \\ ${ }^{2}$ Resident of Neurology, Kerman University of Medical Sciences, Kerman, Iran \\ ${ }^{3}$ Ophthalmology Research Center, Kerman University of Medical Sciences, Kerman, Iran \\ ${ }^{4}$ Private Practice, Mashhad, Iran \\ ${ }^{5}$ Epidemiology research center, Kerman University of medical science, Kerman, Iran
}

*Corresponding author: Zohreh Abna Department of Neurology,Parastar Boulevard, ShafaSreet, Kerman, Iran, Tel:00989133479598; Fax:00983412115803; E-mail: abna.zohreh90@yahoo.com

Received date: Aug 11, 2014, Accepted date: Sep 23, 2014, Published date: Sep 26, 2014

Copyright: (c) 2014 Abna Z, et al. This is an open-access article distributed under the terms of the Creative Commons Attribution License, which permits unrestricted use, distribution, and reproduction in any medium, provided the original author and source are credited.

\begin{abstract}
Background: Multiple Sclerosis (MS) is a neurodegenerative disorder affecting myelinated axons. Cognitive impairments have been observed in patients with MS. Although there are some methods to examine the progress of MS, a tool hasn't been developed to fully correlate MS symptoms with cognitive deficits.

Methods: Among patients referring to Kerman-Iran Shafa Hospital, 60 MS patients were chosen to be included in the study. Their demographic data was obtained and patients filled the Brief International Cognitive Assessment for MS (BICAMS) questionnaire and then underwent OCT. The Chi-square test was used to analyze the frequency of patients with normal and abnormal OCT in the impaired and unimpaired cognition groups. $\mathrm{P}<0.05$ was considered as statistically significant.
\end{abstract}

Results: $20 \%$ of the patients with cognitive impairments had normal OCT, while $71.4 \%$ who were cognitively healthy had normal OCT. the difference between the two groups was statistically significant $(p<0.001)$. 20\% of patients with impaired cognition had physical disabilities, while only $2.9 \%$ with normal cognition had physical disabilities, the statistical difference between these two groups was also statistically significant $(p=0.029)$.

Conclusions: Results of our study indicates that OCT can be used as a screening tool to evaluate the cognitive status of MS patients with $66.6 \%$ and $83.3 \%$ sensitivity and specificity, respectively.

Keywords: Multiple Sclerosis; Optic Coherence Tomography; BICAMS

\section{Introduction}

Multiple Sclerosis (MS) is a debilitating immune mediated illness which has both economic and social burdens [1- 4]. It includes both degenerative and inflammatory components and is manifested by the axonal loss at different levels in the CNS [3-5] which can be diagnosed in its early stages using different methods [6].

MS usually manifests with cognitive deficits [5,7-9], although recently neurologists have become aware of these manifestations [10]. $65-40 \%$ of MS patients show cognitive impairments and these deficits would be observed at any stage of the disease in any progress stage [11]. Cognitive deficits have a great impact on patients' quality of life, thus, measuring the effectiveness of therapeutic agents on these deficits would help in the assessment of treatment progress $[1,6,11]$.

The optic nerve is affected in nearly $50 \%$ of patients $[3,12]$. Axonal loss in the anterior visual pathway is usually a consequence of $\mathrm{ON}$, which could be identified as a thinning of the retinal nerve fiber, measured by methods such as Optic Coherence Tomography (OCT)
$[3,4,12-14]$. This method is easy to use and is an effective way to measure retinal nerve thickness and axonal loss at the retina [3].

Therefore, the objective of this study is to assess the association of cognitive deficits with OCT changes in recently diagnosed MS patients. This would help evaluate if OCT could predict cognitive impairments in MS patients.

\section{Methods and Materials}

Among relapsing-remitting MS patients referring to the MS clinic of Shafa Hospital (Kerman, Iran), 60 subjects with at least two years history of disease were chosen for this study. Patients were initially examined by the ophthalmologist and patients with concomitant ophthalmic diseases such as Glaucoma and Cataract and refractory impairments and those with a history of Optic Neuritis were excluded from the study.

The Brief International Cognitive Assessment for MS (BICAMS) initiative which is optimized for small centers, with perhaps one or few staff members, who may not have NP training, was undertaken in order to recommend a brief and cognitive assessment for MS. BICAMS is particularly focused on international use, to facilitate comparison across settings. An expert committee of twelve 
Citation: Sedighi B, Shafa MA, Abna Z, Ghaseminejad AK, Farahat R et al. (2014) Association of Cognitive deficits with Optical Coherence Tomography changes in Multiple Sclerosis Patients. J Mult Scler 1: 117. doi:10.4172/jmso.1000117

Page 2 of 4

neurologists and neuropsychologists representing the main cultural groups that contributed a lot of data about cognitive dysfunction in MS, was convened. The opinions generated from the meeting were published elsewhere. In brief, the panel recommended one particular test with high reliability and good sensitivity, the Rao adaptation of the revised Brief visuospatial Memory Test (BVMTR), the Symbol Digit Modality Test (SDMT), Consensus was also achieved on optimal measures for the learning and memory criteria in MS patients, time permitting: the initial learning trials of the second edition of the California Verbal Learning Test (CVLT2) [15]. Patients impaired on two or more tests were defined as cognitively impaired [16]. An ROW Score of 9 was considered as the cutoff point. To assess optic nerve thickness, OCT was performed by an expert ophthalmologist. The Optovue device (RTVue, USA) was used for the tests [3]. Demographic data including age, sex and education was gathered using a questionnaire. The Expanded Disability Status Scale (EDSS) (Kurtzke, 1983) was used to score patients impairments [17,18]. Scores more than 6 on EDSS were considered as physically impaired.

After evaluating the axonal loss in the retina and performing BICAMS, data were analyzed using the SPSS software version16 (IBM, USA). To compare the categorical variables among the two groups of unimpaired and impaired patients, the chi-square or Fischer's exact test was used.

Ethical code: K/92/67

\section{Results}

From 60 patients who were evaluated by the BICAMS test for cognitive function, the results are shown in table 1.

\begin{tabular}{|c|c|c|c|c|c|c|c|c|c|c|c|c|c|c|}
\hline \multirow[t]{2}{*}{ Variables } & \multicolumn{2}{|c|}{ Cognition } & \multicolumn{2}{|l|}{ Age } & \multicolumn{2}{|c|}{ Gender } & \multicolumn{2}{|c|}{ Education } & \multicolumn{2}{|c|}{ Duration } & \multicolumn{2}{|c|}{ EDSS } & \multicolumn{2}{|l|}{ OCT } \\
\hline & Normal & Impaired & $<40$ & $\geq 40$ & $\begin{array}{l}\text { Femal } \\
\mathrm{e}\end{array}$ & Male & $\begin{array}{l}<\text { Diplom } \\
\text { a }\end{array}$ & 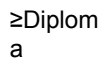 & $<6 y r$ & $\geq 6 \mathrm{yr}$ & $<6$ & $\geq 6$ & Normal & Abnormal \\
\hline Number & 35 & 25 & 35 & 25 & 51 & 9 & 26 & 34 & 25 & 35 & 54 & 6 & 30 & 30 \\
\hline
\end{tabular}

Table 1: The number of each variables.

Of the patients in the impaired cognition group, $15(60 \%)$ were younger than 40 , while on the normal cognition group, $22(62.9 \%)$ were younger than 40 . The impaired cognition group consisted of five female subjects (20\%), while the normal group included four female subjects (\%11.4). 13 (52\%) patients with cognitive disorders and 21
(60\%) normal patients had an education higher than diploma. The difference in terms of disease duration between the impaired group in comparison with the non-impaired group was not statistically significant $(\mathrm{p}=0.070)$ (table 2).

\begin{tabular}{|l|l|l|l|l|l|l|l|l|}
\hline \multirow{2}{*}{ Variables } & \multicolumn{2}{|l}{ Age } & \multicolumn{2}{l|}{ Gender } & \multicolumn{2}{l|}{ Education } & \multicolumn{2}{l|}{ Duration } \\
\cline { 2 - 9 } & $<40 \mathrm{yr}$ & $\geq 40 \mathrm{yr}$ & Male & Female & <Diploma & $\geq$ Diploma & $<6 \mathrm{yr}$ & $\geq 6 \mathrm{yr}$ \\
\hline $\begin{array}{l}\text { Normal } \\
\text { cognition }\end{array}$ & $22(62.9 \%)$ & $13(37.1 \%)$ & $4(11.4 \%)$ & $31(88.6 \%)$ & $14(40 \%)$ & $21(60 \%)$ & $18(51.4 \%)$ & $17(48.6 \%)$ \\
\hline $\begin{array}{l}\text { Impaired } \\
\text { cognition }\end{array}$ & $15(60 \%)$ & $10(40 \%)$ & $5(20 \%)$ & $20(80 \%)$ & $12(48 \%)$ & $13(52 \%)$ & $7(28 \%)$ & $18(72 \%)$ \\
\hline P-Value & 0.8 & & 0.4 & 0.538 & & 0.070 & \\
\hline
\end{tabular}

Table 2: The baseline information of the patients in the two groups.

\begin{tabular}{|l|l|l|l|l|}
\hline \multirow{2}{*}{ Variables } & \multicolumn{2}{|l|}{ EDSS } & \multicolumn{2}{l|}{ OCT } \\
\cline { 2 - 5 } & $<6$ & $\geq 6$ & Normal & Abnormal \\
\hline $\begin{array}{l}\text { Normal } \\
\text { cognition }\end{array}$ & $34(97.1 \%)$ & $1(2.9 \%)$ & $25(71.4 \%)$ & $10(28.6 \%)$ \\
\hline $\begin{array}{l}\text { Impaired } \\
\text { cognition }\end{array}$ & $20(80 \%)$ & $5(20 \%)$ & $5(20 \%)$ & $20(80 \%)$ \\
\hline P-Value & 0.002 & & 0.001 & \\
\hline
\end{tabular}

Results showed that the frequency of physical disability in the impaired group was statistically more when compared to the normal group $(\mathrm{p}=0.029)$.

Comparing the OCT in the two groups showed that normal OCT was statistically more in the group with normal cognition in comparison to the group with impaired cognition $(\mathrm{p}<0.001)$ (Table 3$)$.

\section{Quantitative analysis}

The relation between the BICAMS (SDMT, CVLT-2, and BVMT-R)

Table 3: Frequency of patients with physical disability and abnormal OCT in the impaired and the non-impaired cognition groups.

The frequency of the physical disability, evaluated by the EDSS, was compared among the cognitively impaired and the normal group. and the OCT was assessed using the multiple regression analysis. Regarding the accounted $\mathrm{P}$ values, we can say that the OCT predicts the SDMT component (processing speed) of the BICAMS test at a rate of $64.6 \%$, while BVMT-R and CVLT-2components are not predictable in this way (Table 4). 


\begin{tabular}{|l|l|l|l|l|}
\hline Variables & Standard error & Standard estimate & t Value & P Value \\
\hline Constant & 6.507 & - & 11.289 & 0.000 \\
\hline SDMT & 0.116 & 0.646 & 3.228 & 0.002 \\
\hline CVLT & 0.181 & -0.003 & -0.017 & 0.986 \\
\hline BVMT-R & 0.282 & 0.112 & 0.649 & 0.519 \\
\hline
\end{tabular}

Table 4: Coefficients regression model of BICAMS(SDMT,CVLT-2,BVMT-R) and OCT.

Data analysis using the Pearson correlation coefficient showed that there is significant difference between the OCT and the BICAMS. $(\mathrm{P}=0.000)$ (Table 5).

\begin{tabular}{|l|l|l|}
\hline$P$ & $n$ & rxy \\
\hline 0.000 & 60 & -0.567 \\
\hline
\end{tabular}

Table 5: Pearson correlation coefficient between BICAMS and OCT.

\section{Discussion}

Many methods and tests have been introduced to evaluate the progress of Multiple Sclerosis (MS) [6,10,18]. While some are invasive and costly [3], others are non-invasive and less costly, such as Optical Coherence Tomography (OCT). We used this method to document whether there is an association between OCT changes and cognitive impairments in MS patients. We observed that only $20 \%$ of MS patients with cognitive impairment had normal OCT, while $71.4 \%$ of the patients with non-impaired cognition had normal OCT, therefore we conclude that OCT changes could predict the presence of cognitive impairments in MS patients.

MS patients suffer from cognitive impairments, as shown by previous studies [5,6,8-11], but the extent of these impairments and the methods of measuring them are costly and sometimes invasive, therefore, finding a novel method for the testing of cognitive impairments in MS patients would help clinicians increase the precision of their diagnosis. In a review by Chiaravalloti and DeLuca (2008), they showed that MS patients suffer from: cognitive deficits in their complex attention, efficiency in processing information, executive functioning, processing speed and long-term memory [5]. We used BICAMS in the study to evaluate the cognitive functioning of MS patients [16]. This screening tool was used to split the MS patients into two groups: the cognitively impaired and the non-impaired groups. The Persian version of this test is shown to have good reliability and validity [16]. The presence of more patients with abnormal OCT in the cognitively impaired group compared to the non-impaired group showed that patients suffering from abnormal OCT are at a higher risk of developing cognitive impairments.

There is a vast body of evidence supporting the finding that OCT can detect neuronal axon loss in MS patients $[3,4,13,14]$. In a systematic review by Petzold et al. (2010), showed that MS patients have a lower Retinal Nerve Fiber Level (RNFL) compared to the control group, and patients suffering from Optic Neuritis have a lower RNFL compared to the MS patients without optic neuritis [4]. The current study included patients without a history of optic neuritis, therefore the criteria for the thinning of RNFL was $112.78 \pm 13.2$ micrometer.
There was a significant difference between the cognitively impaired and the non-impaired group in their physical disability, which was measured by the EDSS. While $20 \%$ of the former had physical disability, only $2.9 \%$ of the latter showed signs of physical disability, which might indicate another possible association between cognitive impairments and physical disabilities.

Generally the sensitivity and specificity of the OCT in the prediction of cognition is $\% 66.6$ and $83.3 \%$ respectively.

\section{Conclusion}

MS patients with abnormal OCT are at a higher risk of developing cognitive impairments compared to patients with normal OCT. This finding is of clinical value since it can introduce a new method of assessing cognitive impairments which is easy to use and non-invasive in comparison to other applied methods.

\section{Acknowledgement}

Authors, would like to thank the research deputy of Kerman University of medical sciences for their financial support and all the MS patients who kindly participated in this study.

\section{References}

1. Naci H, Fleurence R, Birt J, Duhig A (2010) Economic burden of multiple sclerosis: a systematic review of the literature. Pharmacoeconomics 28: 363-379.

2. Whetten-Goldstein K, Sloan FA, Goldstein LB, Kulas ED (1998) A comprehensive assessment of the cost of multiple sclerosis in the United States. Mult Scler 4: 419-425.

3. Fjeldstad C, Bemben M, Pardo G (2011) Reduced retinal nerve fiber layer and macular thickness in patients with multiple sclerosis with no history of optic neuritis identified by the use of spectral domain high-definition optical coherence tomography. Journal of Clinical Neuroscience. 18: 1469-1472.

4. Petzold A, de Boer JF, Schippling S, Vermersch P, Kardon R, et al. (2010) Optical coherence tomography in multiple sclerosis: a systematic review and meta-analysis. Lancet Neurol 9: 921-932.

5. Chiaravalloti ND, DeLuca J (2008) Cognitive impairment in multiple sclerosis. Lancet Neurol 7: 1139-1151.

6. Ferreira ML (2010) Cognitive deficits in multiple sclerosis: a systematic review. Arq Neuropsiquiatr 68: 632-641.

7. Benedict RH, Cookfair D, Gavett R, Gunther M, Munschauer F, et al. (2006) Validity of the minimal assessment of cognitive function in multiple sclerosis (MACFIMS). J Int Neuropsychol Soc 12: 549-558.

8. Benedict RH, Munschauer F, Linn R, Miller C, Murphy E, Foley F, et al. (2003) Screening for multiple sclerosis cognitive impairment using a selfadministered 15-item questionnaire. Multiple Sclerosis 9: 95-101. 
Citation: Sedighi B, Shafa MA, Abna Z, Ghaseminejad AK, Farahat R et al. (2014) Association of Cognitive deficits with Optical Coherence Tomography changes in Multiple Sclerosis Patients. J Mult Scler 1: 117. doi:10.4172/jmso.1000117

Page 4 of 4

9. Bobholz JA, Rao SM (2003) Cognitive dysfunction in multiple sclerosis: a review of recent developments. Curr Opin Neurol 16: 283-288.

10. Zipoli V, Goretti B, Hakiki B, Siracusa G, Sorbi S, et al. (2010) Cognitive impairment predicts conversion to multiple sclerosis in clinically isolated syndromes. Mult Scler 16: 62-67.

11. Amato MP, Portaccio E, Zipoli V (2006) Are there protective treatments for cognitive decline in MS? J Neurol Sci 245: 183-186.

12. Cheng H, Laron M, Schiffman JS, Tang RA, Frishman LJ (2007) The relationship between visual field and retinal nerve fiber layer measurements in patients with multiple sclerosis. Investigative ophthalmology \& visual science. 48: 5798-5805.

13. Frohman E, Costello F, Zivadinov R, Stuve O, Conger A, et al. (2006) Optical coherence tomography in multiple sclerosis. Lancet Neurol 5: 853-863.

14. Siger M, Dziegielewski K, Jasek L, Bieniek M, Nicpan A, et al. (2008) Optical coherence tomography in multiple sclerosis: thickness of the retinal nerve fiber layer as a potential measure of axonal loss and brain atrophy. J Neurol 255: 1555-1560.

15. Benedict RH, Amato MP, Boringa J, Brochet B, Foley F, et al. (2012) Brief International Cognitive Assessment for MS (BICAMS): international standards for validation. BMC Neurol 12: 55 .

16. Eshaghi A, Riyahi-Alam S, Roostaei T, Haeri G, Aghsaei A, et al. (2012) Validity and reliability of a Persian translation of the Minimal Assessment of Cognitive Function in Multiple Sclerosis (MACFIMS). Clin Neuropsychol 26: 975-984.

17. Barkhof F (1999) MRI in multiple sclerosis: correlation with expanded disability status scale (EDSS). Mult Scler 5: 283-286.

18. Kurtzke JF (1983) Rating neurologic impairment in multiple sclerosis: an expanded disability status scale (EDSS). Neurology 33: 1444-1452. 